\title{
INTOLERÂNCIA À LACTOSE: DEFICIÊNCIA DE CÁLCIO
}

\author{
Ana Luiza Gandra ${ }^{1}$ \\ Bruna Gonçalves Flausino ${ }^{2}$ \\ Dóris Cristina Freitas Dolabela ${ }^{3}$ \\ Douglas Santiago ${ }^{4}$ \\ Júnia Lara Martins ${ }^{5}$ \\ Lhorena Paula da Silva Lourenço 6 \\ Arilton Januário Bacelar Júnior ${ }^{7}$
}

RESUMO: Denomina-se hipolactase a deficiência da enzima lactase responsável pela hidrólisação do dissacarídeo presente no leite, diferente da alergia, que é uma reação imunológica devido a proteína não ser reconhecida pelo organismo, podendo ser confundida por sua semelhança dos sintomas. $\mathrm{Na}$ hipolactase, á lactose não é absorvida pelo intestino delgado, sendo transformada pelas bactérias em ácidos graxos liberando assim, gases que geram desconforto abdominal. Á apresentação de sintomas varia de acordo com a quantidade de lactose ingerida, podendo não apresentar sintomas quando ingerida em baixa quantidade. O tratamento da hipolactase será feito através da ingestão da enzima lactase ou da retirada de produtos que contenham lactose. Diante da menor atividade da lactase a absorção de cálcio se vê comprometida já que esse é um fator importante para absorção. Para alcançar os objetivos propostos, utilizou-se como recurso metodológico, a pesquisa bibliográfica exploratória com caráter descritivo, tendo como bases documentos extraídos de dados virtuais Scientific Electronic Library Online (Sciello), Google acadêmico e demais sites científicos, para obtenção de artigos, teses, monografias, dissertações e livros envolvidos no tema proposto.

Palavras-chave: Hipolactase. Absorção. Deficiência.

ABSTRACT: Hypolactase is the deficiency of the lactase enzyme responsible for hydrolyzing the disaccharide present in milk, unlike allergy, which is an immunological reaction due to the protein not being recognized by the body, which may be confused by its similarity of symptoms. In hypolactase, lactose is not absorbed by the small intestine, being

'Acadêmico do curso de graduação de Biomedicina da Faculdade Única de Ipatinga/MG;

${ }^{2}$ Acadêmico do curso de graduação de Biomedicina da Faculdade Única de Ipatinga/MG;

${ }^{3}$ Acadêmico do curso de graduação de Biomedicina da Faculdade Única de Ipatinga/MG;

${ }^{4}$ Acadêmico do curso de graduação de Biomedicina da Faculdade Única de Ipatinga/MG;

5 Acadêmico do curso de graduação de Biomedicina da Faculdade Única de Ipatinga/MG;

${ }^{6}$ Professor de Imunologia e Parasitologia da Faculdade Única de Ipatinga M.G. Faculdade Presidente

Antônio Carlos, E-mail: Ipatinga.dr.arilton@alumni.usp.br

7 Professor de Imunologia e Parasitologia da Faculdade Única de Ipatinga M.G. Faculdade Presidente

Antônio Carlos. E-mail: Ipatinga.dr.arilton@alumni.usp.br 
transformed by bacteria into fatty acids, thus releasing gases that generate abdominal discomfort. The presentation of symptoms varies according to the amount of lactose ingested, and it may not show symptoms when ingested in low amounts. The treatment of hypolactase will be done through the ingestion of the lactase enzyme or the removal of products that contain lactose. Due to the lower lactase activity, calcium absorption is compromised as this is an important factor for absorption. To achieve the proposed objectives, exploratory bibliographic research with a descriptive character was used as a methodological resource, based on documents extracted from virtual data Scientific Electronic Library Online (Sciello), academic Google and other scientific sites, to obtain articles, theses , monographs, dissertations and books involved in the proposed theme.

Keywords: hypolactase. Absorption. Deficiency.

\section{INTRODUÇÃO}

A intolerância à lactose é uma reação que não tem relação com o sistema imunológico, ocorrendo devido à deficiência da enzima lactase, sendo entendida como uma intolerância alimentar. A lactose é o carboidrato do leite, um carboidrato complexo que o nosso organismo não consegue absorver se não houver a fragmentação em duas moléculas pequenas (ANVISA, 2016)

As manifestações clínicas nos pacientes com intolerância a lactose são gastrointestinais, os mais comuns são os vômitos e as diarreias, demorando até 2 horas para aparecem as manifestações clínicas dos intolerantes. Se o indivíduo ingerir baixas quantidades de lactose ele não apresentará sintomas gastrointestinais (BATISTA et al, p. 4120, 2018).

Existem vários tipos de diagnósticos, dentre os quais podemos citar: os métodos cromatográficos, citado por Morlock em 2014 e crioscopia, citado por Rodrigues Júnior em 2oi6 (TORRES et al, p. 96, 2016).

Cerca de $70 \%$ da população mundial adulta apresenta deficiência em níveis de lactase, sendo que na Europa tem sido relatada a variação entre $4 \%$ na Dinamarca e Irlanda e $56 \%$ na Itália. Na América do Sul, África e Ásia, mais de $50 \%$ da população apresenta intolerância à lactose. Já em alguns países asiáticos, esta taxa é de quase Ioo\% (LULE et al., 2016).

Segundo Reis em 2003 a intolerância a lactose tem ocorrência primária, secundária e congênita. Evidenciando que a intolerância à lactose e a alergia aoleite possui alguns sintomas e reações similar apesar de serem duas coisas diferentes. A diferença é que a intolerância a lactose ocorre por um funcionamento anormal na produção da enzima lactase, a alergia ao leite envolve sistema imunológico (PEREIRA et al, p. 6o, 2012). 
Elucida-nos Vogel (200o), que no tratamento a intolerância, não é permitido o consumo de produtos com muita lactose ou mesmo a ingestão da enzima lactase por produtos lácteos ou porções menores de leite e laticínios dos quais a lactose foi removida pela fermentação, por exemplo iogurte ou coalhada (VOGEL, 200o).

Muitos alimentos que contém a lactose têm cálcio em sua composição, sendo que o mesmo tem várias funções em nosso corpo, como por exemplo, ele atua nos músculos, auxiliando no processo de contração, como também nos nossos ossos e dentes (BALDO, 2008).

No seguinte trabalho vamos abordar sobre a intolerância a lactose e a deficiência de cálcio no organismo, para expormos sobre como o cálcio está presente nos componentes de lactose, bem como lidar com essa ausência

\section{MATERIAL E MÉTODOS}

Através de revisão da literatura obtida por meio das ferramentas de busca Scielo, sistema de biblioteca UFMG, ERIC-Instituto de Ciências da Educação, Google acadêmico

e sites do Ministério da Saúde e ANVISA, utilizando as palavras chaves Hipolactase, absorção e deficiência, foram selecionados artigos científicos, dissertações e teses, para a elaboração de trabalho com caráter descritivo. Os critérios de inclusão de documentos foram a data de publicação, dando preferência por publicações dos últimos cinco anos, qualidade da publicação, optando pela não utilização de artigos de periódicos não indexados e de monografias, assim como a relevância da publicação para o trabalho e para o assunto. Foram excluídos artigos de e monografias, que não apresenta relevância da publicação para o trabalho e para o assunto. Os artigos foram analisados e selecionados criteriosamente conforme a relevância para o estudo, e em seguida foram agrupados por assunto. Posteriormente ocorreu a discussão, construção e apresentação da revisão de literatura.

\section{DESENVOLVIMENTO}

\section{Diferença entre Intolerância e Alergia}

A alergia alimentar é uma reação adversa imunologicamente desencadeada de mecanismos de ação do antígeno causador, que proporciona sinais e sintomas após a ingestão desse alimento. No caso da alergia ás proteínas do leite da vaca o agente causador é 
encontrado normalmente no leite e também em seus derivados. Citados como a caseína, lactoglobulina, lactoalbumina, soroalbumina, imunoglobulinas. Apesar de serem alimentos que ajudam no desenvolvimento e o organismo tenha a capacidade de digeri-las, muitas vezes ás proteínas do leite não são reconhecidas pelo sistema imune, causando o desenvolvimento de alergias. Portanto, quando isso acontece, identifica-se que o paciente tenha alergia à proteína do leite de vaca, trazendo assim, a necessidade de uma terapia nutricional (GASPARIN et al, p. 108, 2010).

A intolerância alimentar pode ser definida quando ocorre uma resposta diferente a um alimento ou um complementar, sem que exista intervenções do sistema imunológico. Podendo ocorrer devido à ação de toxinas produzidas por bactérias e fungos, agentes farmacológicos ou erros metabólicos por deficiência enzimática. A intolerância a lactose é frequentemente encontrada e pode ser diagnosticada como a incapacidade do organismo de absorver a lactose (VIEIRA et al, 2002).

Portanto, conclui-se que a alergia à proteína do leite de vaca está relacionada às reações imunológicas, devido ser causada pela defesa a uma proteína não reconhecida pelo organismo, divergindo, da intolerância à lactose, que é uma alteração metabólica por falta de uma enzima (lactase), tendo como característica a não absorção do açúcar presente no leite de vaca (MACHADO et al, p. 62, 2012).

\section{FISIOPATOLOGIA}

A lactose é um dissacarídeo presente no leite formado pela glicose e galactose, que através monossacarídeo glicose é feito pelas glândulas exócrinas dos mamíferos, ele provê de carboidrato o rebento durante a amamentação através da glicose para suprir o componente carboidrato durante a lactação (QUILICI et al, p. 3, 2004).

Devido a deficiência na enzima lactasse, a lactose é hidrolisada em glicose e galactose, que se acumula na mucosa intestinal. A galactose metabolizada no fígado é transformada em glicose, depois entra no pool de glicose. A galactose que não é transformada em glicose, é abolida do organismo pela urina ou pelas hemácias. A quantidade da enzima lactase acaba sendo maior no jejuno e no duodeno sendo menor. A lactose que não for absorvida no intestino delgado, acaba sendo transformada pelas bactérias na mucosa em ácidos graxos no colón (MATTAR et al, p.232, 2010). 
Neste contexto, a deficiência da enzima lactase se apresenta tão somente quando a pessoa aumenta o consumo de leite e derivados, ou quando está relacionada à outra causa, como a diarreia seu surgimento é latente enquanto a quantidade de consumo da lactose for pequena (SABRA, 1994).

A ocorrência primária da intolerância a lactose é a que tem mais incidência em todas as faixas etárias, tendo como causa a ausência da enzima lactase, total ou parcial (Heyman, 2006)

A hipolactasia secundaria está relacionada com danos no intestino delgado, tendo consequência o intestino preso e outras diversas condições fisiopatológicas. Sendo assim quando a lesão da mucosa gastrointestinal é regenerada é totalmente reversível, estabelecendo um tratamento (POUZAS, BARACHO, CERVONE E UCELLI, 2015).

A ocorrência congênita é aquela que nasce com o indivíduo, onde tem como causa a ausência da enzima lactase no jejuno, tendo como principal sintoma a diarreia ao ingerir a alimentos que contêm lactose (BERNE, 2004).

\section{O Cálcio}

Sabe-se que atualmente, 50\% dos adultos no mundo são intolerantes a lactose, o tratamento para essa condição em primeiro lugar é redução ou restrição da ingestão de alimentos que contenha lactose, perdendo a maior fonte de cálcio para uma dieta rica neste elemento (Da Silva, 2017).

O cálcio é um elemento essencial para o nosso organismo e o cátion mais abundante no mesmo, necessário para o crescimento e desenvolvimento dos ossos e dentes; a concentração de cálcio nos tecidos é variável e a maior parte deste $(98,9 \%)$, se concentra depositado no tecido ósseo, (I\%) se encontra no interior das células, principalmente no retículo endoplasmático e mitocôndrias, e (0,1\%) é a pequena porcentagem de cálcio livre presente nos líquidos extracelulares. O cálcio livre nos líquidos extracelulares desempenha diversos papeis biológicos essenciais como cofator enzimático, em processos biológicos e atividade hormonal, dentre outras funções. Uma alteração da concentração de cálcio nos líquidos corporais acarreta grandes disfunções no organismo (Da Silva, 2017). 


\section{ABSORÇÃO}

A ingestão diária de alimentos é a única fonte de reposição de cálcio; em média a ingestão dos alimentos é cerca de $1000 \mathrm{mg} / \mathrm{dl}$, equivalente a quantidade presente em um litro de leite (Da Silva, 2017).

A absorção deste elemento normalmente é de $20 \%$ a $30 \%$ da quantidade de cálcio ingerida, devido a que o intestino tem dificuldade de absorver a forma iônica do cálcio, e outra parte é perdida com a secreção dos sucos digestórios e a descamação de células da mucosa intestinal (Motas-Blancas, 1999).

Por outro lado, o organismo possui uma adaptação, devido a que a porcentagem de cálcio absorvida aumenta conforme é diminuída a sua ingestão, provocando a estimulo a paratireoide liberando o paratormônio $(\mathrm{PTH})$. Estimulando a reabsorção tubular renal de cálcio e aumentando a atividade dos osteoclastos nos locais onde ocorre reabsorção e ativa a vitamina D para aumentar a absorção intestinal de cálcio. Resultando no aumento da atividade do transporte ativo; já a difusão passiva possui um maior efeito quando a ingestão de cálcio aumenta, devido a que o transporte ativo fica saturado com grandes quantidades de cálcio ao contrário da difusão passiva que é o mecanismo predominante de absorção de grandes quantidades (PEREIRA, 2009).

O cálcio é absorvido no intestino delgado ao longo de seus segmentos, através de transporte ativo e transporte passivo, paralelamente. Segundo (Ernesto motas), podemos afirmar que a absorção ocorrerá de forma mais eficiente ou menos, dependendo do $\mathrm{pH}$ do meio onde estiver concentrando o cálcio no intestino sendo que, conforme aumenta a alcalinidade a quantidade de cálcio absorvida diminui; portanto, o transporte ativo será mais eficaz no duodeno e jejuno proximal, onde o $\mathrm{pH}$ é mais ácido e onde está presente a calbindina, responsável por contribuir ao transporte intracelular de cálcio; já no jejuno distal e íleo ocorre a absorção se dá por meio do transporte passivo (difusão) (Barbosa, 20II).

\section{CÁLCIO E LACTOSE}

A relação entre o cálcio e lactose, ocorre devido a fatores que modificam a sua absorção, como a presença da lactose em alguns alimentos, que pode auxiliar no aumento da osmolaridade e a solubilidade, que aumenta o transporte passivo (PEREIRA, 2009). 
Para comprovar essa relação entre a absorção de cálcio e a lactose, realizou-se uma pesquisa por Bernard Cochet, André Jung, Marthe Griessen, Paul Bartholdi, Philippe Schaller e Alfred Donath. Onde estudaram o efeito da lactose no intestino de I2 voluntários normais, e 7 voluntários com deficiência de lactase. Durante o processo observou-se que o grupo com os níveis normais de lactase, a lactose prolongava o tempo de absorção a uma taxa muito elevada, consequentemente aumentando a fração total de cálcio absorvido. Por outro lado, o grupo com deficiência de lactase, ocorreu a diminuição da taxa máxima de absorção de cálcio. Com este estudo COCHET et al. 1983, concluíram que o efeito da lactose sobre a absorção do cálcio depende da atividade da lactase, que melhora a absorção em pessoas com uma atividade normal desta enzima e em pessoas com uma deficiência de lactase ela diminui a absorção de cálcio (COCHET et al, 1983).

\section{CONCLUSÃO}

Com base no que foi apresentado, pode se entender que por mais que a hipolactase seja uma reação fisiológica natural, pode se tornar um processo patológico crónico ou agudo dependendo da quantidade que for ingerida. Vale ressaltar também que a alergia a proteina do leite está relacionada a sistema imunológico, já a intolerância não. Além disso, é possível compreender que a deficiência desta enzima pode provocar a mal absorção do cálcio, pois ausenta a hidrolise da lactose que estimula a maior absorção.

\section{REFERÊNCIAS}

AGÊNCIA NACIONAL DE VIGILÂNCIA SANITÁRIA (Brasil). Perguntas e respostas sobre Rotulagem de Alimentos Alergênicos. Gerência de Avaliação de Risco e Eficácia para Alegações. Gerência Geral de Alimentos. Brasília, DF: ANVISA, 2016. 27 p.

VOGEL, F. Genética Humana: Problemas e abordagens. 3. ed. Rio de Janeiro: Guanabara Koogan, 2000. 508-51I p.

BATISTA, A. P. J. Lactose em alimentos industrializados: avaliação da disponibilidade da informação de quantidade. MG. SP: 2018. 4120 p. 
TORRES, S. T. C. C. S. P. Hidrólise da lactose e produção de leite em pó: aspectos tecnológicos. SP, MG. França: 2016. 96 p.

PEREIRA, B. K. P. R. P. Lácteos com baixo teor de lactose: uma necessidade para portadores de má digestão da lactose e um nicho de mercado. Juiz de Fora, MG: 2012. 60 p.

MATTAR, M. Intolerância à lactose: mudança de paradigmas com a biologia molecular. São Paulo, SP: 2010. 232 p.

BARBOSA, A. Intolerância à lactose e suas consequências no metabolismo do cálcio. Maringá: 20II. 82 p.

PINTO, B. A. S. O uso de probióticos para o tratamento do quadro de Intolerância à Lactose. $\mathrm{SP}: 2015.58 \mathrm{p}$.

GASPARIN, T. A. Alergia à proteína do leite de vaca versus intelerância à lactose: as diferenças e semelhanças. PR: 2010. 108 p.

MACHADO, P. S. Aptidão do enfermeiro no auxílio à nutrição de lactente com intolerância à lactose e alergia à proteína do leite da vaca. SP: 2013. $62 \mathrm{p}$.

DA SILVA. C. M. E C A intolerância a lactose e as consequências na absorção do cálcio. Rev. Eletrôn. Atualiza Saúde | Salvador, v. 6, n. 6, p. 29-35, jul. /dez. 2017

MOTAS-BLANCAS. E Los mecanismos de absorción de calcio y los modificadores de absorción con base para la elaboración de una dieta de bajo costo para pacientes osteoporóticas - Gac Méd Méx Vol. 135 No. 3, 1999 
GISELLE A. P. PEREIRA Cálcio dietético - estratégias para otimizar o consumo Rev Bras Reumatol 2009;49(2):164-80

BARBOSA. C. R. - intolerância à lactose e suas consequências no metabolismo do cálcio Revista Saúde e Pesquisa, v. 4, n. I, p. 8I-86, jan. /abr. 20II -ISSN I983-I87o

COCHET, B. Effects of Lactose on Intestinal Calcium Absorption in Normal and LactaseDeficient Subjects GASTROENTEROLOGY 1983;84:935-4 